Research Article

\title{
Creep Fracture Characteristics of Fractured Rock Mass Strengthened with Toughened Epoxy Resin
}

\author{
Jun Wang $\left(\mathbb{D}^{1}{ }^{1}\right.$ Junjie Xu, ${ }^{1}$ Zhipeng Nie, ${ }^{1}$ Lin Liu, ${ }^{1}$ Min Qin, ${ }^{2}$ and Rongzi Ou ${ }^{3}$ \\ ${ }^{1}$ School of Building Engineering, Hunan Institute of Engineering, Xiangtan 411104, Hunan, China \\ ${ }^{2}$ Xiang Jiankezhi Engineering Co., Ltd., Changsha 410000, Hunan, China \\ ${ }^{3}$ Jing Tong Space Technology (Heyuan) Co., Ltd., Heyuan 517001, Guangdong, China
}

Correspondence should be addressed to Jun Wang; 277210509@qq.com

Received 1 July 2021; Accepted 29 July 2021; Published 24 August 2021

Academic Editor: Alessio Cascardi

Copyright (C) 2021 Jun Wang et al. This is an open access article distributed under the Creative Commons Attribution License, which permits unrestricted use, distribution, and reproduction in any medium, provided the original work is properly cited.

For improving the toughness and long-term strength of the fractured rock mass reinforced with epoxy resin and reducing the opening displacement of the crack tip, three types of converging cracks are established according to the deformation and failure characteristics of the rock mass, structural planes, and epoxy resin composite structure. The stress intensity factor of the type II compound crack and the analytical formula of the crack surface tip opening displacement are obtained. An improved Kelvin nonlinear creep model is proposed. Through the creep isochronous curve, the time and long-term strength of accelerated creep failure are obtained, as well as creep rupture coupling characteristics. The ductile plastic deformation is used to characterize the toughness, and the toughness of epoxy resin is enhanced by adding mud powder, and the relationship between toughness and long-term strength is established. Combined with experimental verification, when the drying mud powder content is $20 \%$, the toughness of the epoxy resin has a good correlation with the long-term strength; when the mud powder content exceeds $30 \%$, its ductility and long-term strength decrease, and at the same time the toughness effect is significantly weakened. The research results can provide a useful reference for toughened epoxy resin to strengthen fractured rock mass engineering.

\section{Introduction}

Epoxy resin is a kind of organic polymer compound, which has the advantages of high strength, impact resistance, and high hardness. It is one of the most commonly used engineering plastics. In addition, it is widely used in building waterproofs, mechanical parts, toys, shell materials, and other fields. At present, the research of epoxy resin focuses on toughening, water resistance, fatigue mechanics, engineering reinforcement, and so on. Many scholars have carried out a lot of theoretical and experimental research studies $[1,2]$. Subsequently, they have made a lot of research achievements in toughening measures, fracture deformation characteristics, long-term strength, and so on. They have developed glass fiber epoxy resin, steel fiber epoxy resin, steel fiber epoxy resin, steel fiber epoxy resin, and so on. Nano epoxy resin, and other new composite resin functional materials [3], which can further improve the mechanical properties For example, Yang et al. [4] obtained that when the content of silicone rubber was $6 \mathrm{phr}$, the heat resistance, rheological properties, and impact strength of the mixture of four curing agents and $\mathrm{ABS} / \mathrm{MVQ}$ reached the best; $\mathrm{Xu}$ et al. [5] put forward a toughening method of epoxy resin through a large number of mechanical experiments, which has been effectively applied in many projects; Peng et al. [6] successfully applied epoxy resin as structural adhesive in building reinforcement and fully mobilized the strength of concrete. The above research results are all based on the instantaneous toughening strength of epoxy resin and crackfree reinforcement materials. The mechanical properties and strength of cementitious materials are studied under the assumption that cementitious materials are continuous media and only linear rheological properties are considered. However, in the engineering practice of epoxy resin strengthening, underground building structures, fragmental rock structures, and underground caverns, there are many 
factors such as poor geological environment conditions, significant structural discreteness and large deformation of reinforcement materials and various forms of crack expansion which are bound to have an important impact on the ductile plastic deformation and long-term strength of epoxy resin. In addition, the relationship between epoxy resin toughening and long-term strength is complex, and it is difficult to monitor in real time. At the same time, many problems such as long-term strength, composite converging crack deformation, accelerated failure time, and ductile yield failure of epoxy resin reinforced composite have not been solved, and there are few related literatures. Based on the deformation evolution characteristics and isochron curves of three kinds of converging cracks, a nonlinear element model is established, and then theoretical derivation and experimental verification are carried out to obtain the stress intensity factor, opening displacement, and fracture accelerated deformation failure time of the strengthened structure. Furthermore, the correlation expression between toughness and long-term strength is established, which provides a reference for the toughening and strengthening of epoxy resin. In the present article, the theory of fracture creep coupling mechanical properties of reinforced structures and the engineering application of composite resin functional materials can be used for reference.

\section{Mechanical Properties and Strengthening Mechanism of Hard and Brittle Materials}

2.1. Failure Characteristics. The hard brittle mechanical properties of epoxy resin refer to that under the peak load; when the failure occurs, the deformation is small and the time is short. There are only two processes of elastic stage and strength failure; especially under the action of overweight load, the brittle failure is more significant $[2,7]$, which is different from the ductile yield platform and residual strength when the rubber plastic failure occurs. Simultaneously, the two failure forms are shown in Figure 1.

Epoxy resin molecules have an adsorption effect and can adhere to solid materials after chemical reaction with the curing agents. It is often used to fill cracks in metal, rock, and ceramic structures, such as concrete crack repair, underground tunnel crack rock reinforcement, and underwater concrete crack seepage prevention. Then, the crack rock reinforcement is shown in Figure 2.

According to the plastic failure characteristics of epoxy resin, the method of improving ductility deformation is used to prevent hard brittle failure. The composite material modification is one of the effective measures to improve ductility, such as adding polymer toughening agent, particle material, and fiber materials [7]. After modification, the toughness of epoxy resin increases, but the cracks of the fractured rock mass will still nucleate and expand under long-term load. Thus, the crack propagation condition, propagation morphology, accelerated deformation, and fracture time of this kind of composite crack are difficult problems in the long-term strength study of epoxy resin reinforced fractured rock mass.

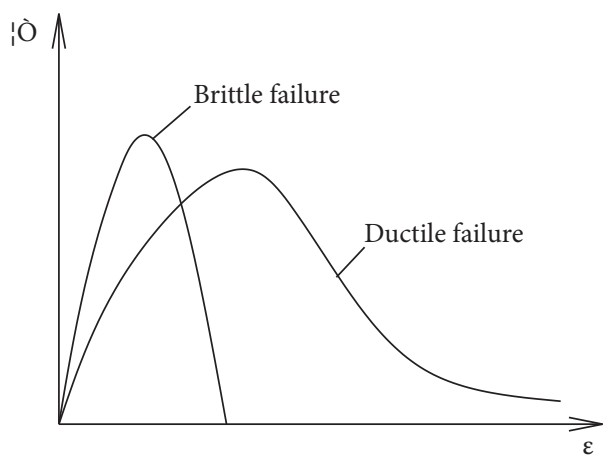

Figure 1: Fracture model.

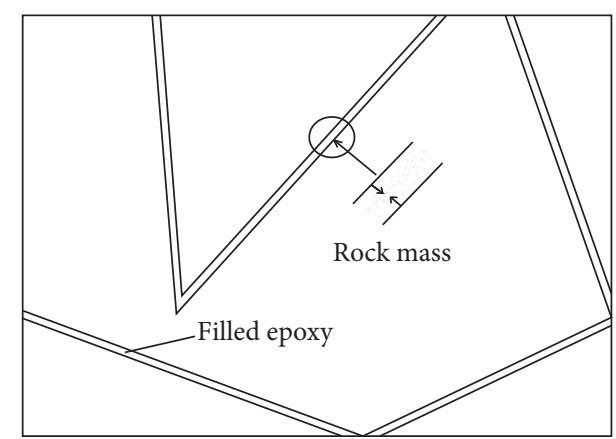

Figure 2: Filled crack and adhesiveness of epoxy.

2.2. Toughness Characteristics. Epoxy resin often increases toughness and adhesion by adding organic polymer toughening agents such as carboxyl terminated liquid nitrile rubber and liquid silicone rubber. These composites still have a certain bond strength after serving in a warm and humid environments for a period of time. However, the quantitative characterization of epoxy resin toughness and its relationship with long-term strength are rarely reported. Some scholars use the plastic deformation at yield failure or the reduction of ultimate deformation to characterize toughness, namely, deformation toughness. Some scholars also use plastic yield limit to characterize toughness, that is, strength toughness. The physical meaning of these two characterization methods is clear, and both plastic deformation and yield strength can be obtained through experiments $[5,8]$. However, under different loads, the strength and plastic deformation rate of toughened epoxy resin are different, and the toughness error characterized by instantaneous value is also large, which has been confirmed by engineering [8]. According to the ductile failure characteristics of toughened epoxy resin, it has its advantages to characterize the toughness by aging plastic deformation, which can track the time-varying characteristics of toughness in real time. When the accelerated failure occurs, this plastic deformation is the maximum extent of toughness. At the same time, it can also fully consider the time-varying characteristics of deformation and failure of toughened epoxy resin:

$$
\begin{aligned}
R_{T} & =\varepsilon_{p}(\sigma, t), \\
R_{T \max } & =\varepsilon_{p}\left(\sigma, t_{p}\right),
\end{aligned}
$$


where $R_{T}$ is the toughness of epoxy resin, $\varepsilon_{p}$ is the plastic deformation and is related to the external load and time, $\sigma$ is the external load, and $t$ and $t_{p}$ are the time and accelerated deformation failure time, respectively.

2.3. Fracture Characteristics. Rock mass is the product of geological process. In the process of rock forming, a large number of microstructures such as fractures and cracks are formed. With the influence of artificial activity, these microstructures nucleate and expand, forming a large number of converging cracks, which are bound to have an important impact on the stability of rock mass engineering. Thus, the main forms of this kind of converging cracks are converging crack tips, converging crack tip and converging crack, and penetrating crack, as shown in Figure 3.

The fracture deformation of fractured rock mass is mainly caused by the tensile shear stress and compressive shear stress on the fracture surface, which drives the nucleation, expansion, and connection of fractures, resulting in fracture failure of the rock mass. Under the condition of external load, the main cracks of the rock mass produce branch cracks, which exist in the form of airfoil and secondary cracks, as shown in Figure 2. Additionally, the cracks are mainly tension shear and compression shear composite stress states, as shown in Figure 4. The fracture failure of tension shear crack is more significant than that of compression shear crack, as shown in Figure 5. Therefore, in this paper, the fracture mechanics analysis under composite stress condition is carried out for the intersection of two symmetrical cracks.

Under the condition of tension shear and compression shear stress, the local stress concentration at the crack tip of the fractured rock mass causes the failure of the rock bridge at the crack tip and forms converging cracks (see Figure 3(a)). When the stress at the crack tip exceeds the critical propagation force, it induces the crack tips to converge to each other (see Figure 3(b)) and increases with the extension of the plastic zone. Then, the energy of the crack surface is completely released, and finally the crack passes through and converges, resulting in the fracture failure of the cracked rock mass. The mechanical condition of the reinforced structure of fractured rock mass is very complex, which often occurs as I, II, and III mixed mode cracks. According to the fracture characteristics of rock mass under tensile and shear stress conditions, this paper studies the effect of stress intensity factor (SIF) and geometric distribution of cracks on SIF by using I-II composite cracks (central crack, diagonal crack, and edge cracks). The propagation direction of composite cracks, the geometric characteristics of three kinds of cracks, the stress intensity factor (SIF), and the geometric distribution of cracks are further studied. The boundary stress conditions are shown in Figure 6.

Combined with the crack geometry and stress boundary conditions in Figure 6, the stress intensity factor of rock mass with symmetrical cracks is obtained by using weight function analysis [8]:

$$
K=\delta \sigma \sqrt{\pi a} \sin ^{2} \beta,
$$

following

$$
\begin{aligned}
\delta & =\int_{0}^{a \sin \beta} \frac{\sigma(x)}{\sigma \sin ^{2} \beta} \cdot \frac{m(\gamma, X)}{\sqrt{\pi a \sin \beta / W}} \mathrm{~d} x, \\
\gamma & =\frac{a}{W} \sin \beta, \\
X & =\frac{x}{W}
\end{aligned}
$$

where $x$ is the geometric distribution coordinate of the crack, $\sigma(x)$ is the crack stress of the rock mass without crack, $\sigma$ is the reference stress (only causes the stress intensity factor and does not show displacement), $a$ is the half length of the crack, $\beta$ is the angle between the external load and the crack, $W$ is the width of the crack, $m(\gamma, X)$ is the weight function, and $\gamma$ and $X$ are the dimensionless factor, respectively.

Combined with the knowledge of composite crack fracture, the stress intensity factors at the point a of the mode I-II composite crack confluence system were established:

$$
\begin{aligned}
K_{\mathrm{I}} & =\delta \sigma \sqrt{\pi a} \sin ^{2} \beta, \\
K_{\mathrm{II}} & =\delta \sigma \sqrt{\pi a} \sin \beta \cos \beta .
\end{aligned}
$$

According to equation (3), the weight function, $m(\gamma, X)$, is obtained:

$$
m(\gamma, X)=\frac{4 G}{(\kappa+1) \sigma \sqrt{\pi a} \sin ^{2} \beta} \cdot \frac{\partial u(\gamma, x)}{\partial a},
$$

following

$$
\kappa= \begin{cases}3-4 v, & \text { plane strain, } \\ \frac{3-v}{1+v}, & \text { plane stress, }\end{cases}
$$

where $u(\gamma, X)$ is the opening displacement at the crack surface tip, $a$ is the half length of the crack, and $G$ is the shear modulus.

The opening displacement of the crack tip, $u(\gamma, x)$, is obtained from the load stress condition in Figure 6:

$$
\begin{aligned}
u(\gamma, X)= & \frac{\sigma \gamma \sin ^{2} \beta}{\sqrt{2 E^{*}}}\left[4 \delta(\gamma)+\frac{\sqrt{2} \pi \Phi(\gamma)-8 / 3 \gamma \delta(\gamma)}{2 / 5}\right] \\
& \cdot\left(1-\frac{x}{a \sin \beta}\right)^{3 / 2},
\end{aligned}
$$

following 


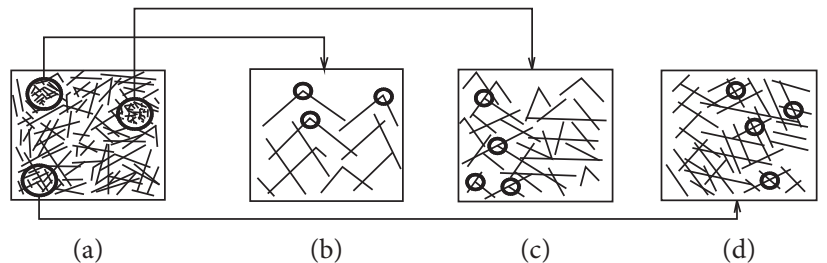

FiguRE 3: Distribution of crack rock mass: (a) cracked rock mass; (b) converging crack tips; (c) converging crack tip and converging crack; (d) penetrating crack.

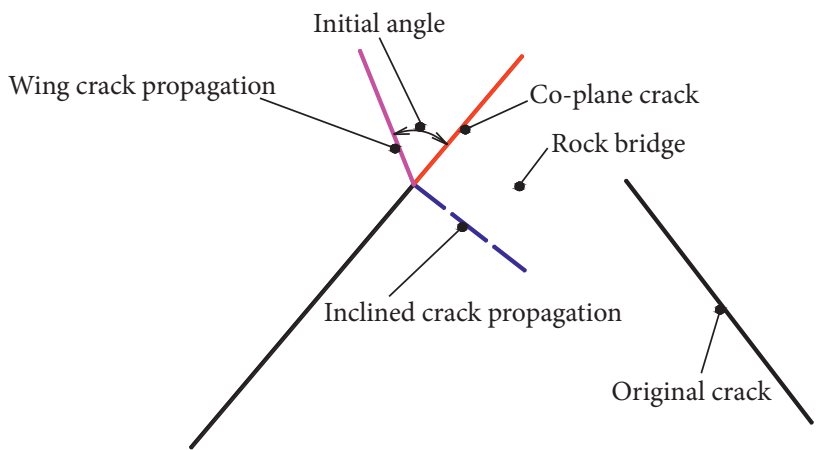

FIgURE 4: Distribution of stress concentration at crack region.

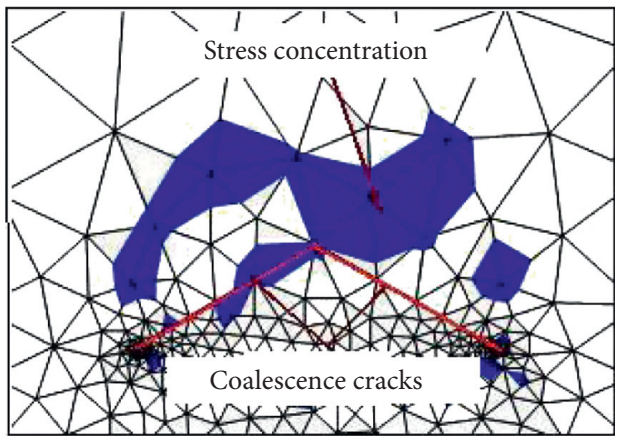

FIgURE 5: Distribution of stress concentration at crack region.

$$
\begin{aligned}
\Phi(\gamma) & =\frac{1}{\gamma^{2}} \int_{0}^{\gamma} \varepsilon \delta^{2}(\varepsilon) \mathrm{d} \varepsilon, \\
E^{*} & = \begin{cases}E, & \text { plane strain, } \\
\frac{E}{\left(1-v^{2}\right)}, & \text { plane stress, }\end{cases}
\end{aligned}
$$

where $\varepsilon$ is the variable and $E$ and $v$ are the elastic constants of the material.

Discreteness occurs in the calculation of the dimensionless factors influenced by the crack width. For the mode I and mode II crack, the increase in crack width will decrease the stress intensity factor. The increase in the angle will impair the influence of the crack width on the factor.

According to the opening displacement of the crack tip the angle between the crack propagation, the external load was proposed (equation (6)). Then, two symmetric coalesced cracks will propagate along the symmetric axis. For the three coalesced cracks, the same conclusion can be drawn. Therefore, under certain external load and boundary stress conditions, the stress intensity factor of the converging crack is affected by the angle between the external load and the crack surface and the ratio of the crack half-length to the crack width.

\section{Creep Mechanics and Long-Term Strength Characteristics}

3.1. Strength of Fractured Rock Mass. Rock mass is a natural structure composed of rock and structural plane. There are a lot of weak structural planes such as joints, fissures, and faults in engineering rock mass. Structural plane determines the strength and stability of rock mass. Therefore, controlling the deformation and improving the stability of engineering rock mass are mainly realized by strengthening the strength of structural plane and improving the mechanical parameters of rock mass. Then, epoxy resin as a grouting material can increase the shear strength of 


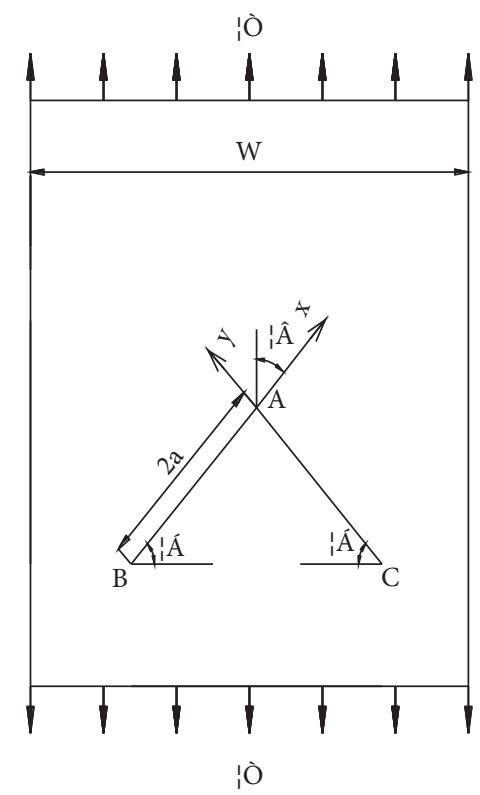

(a)

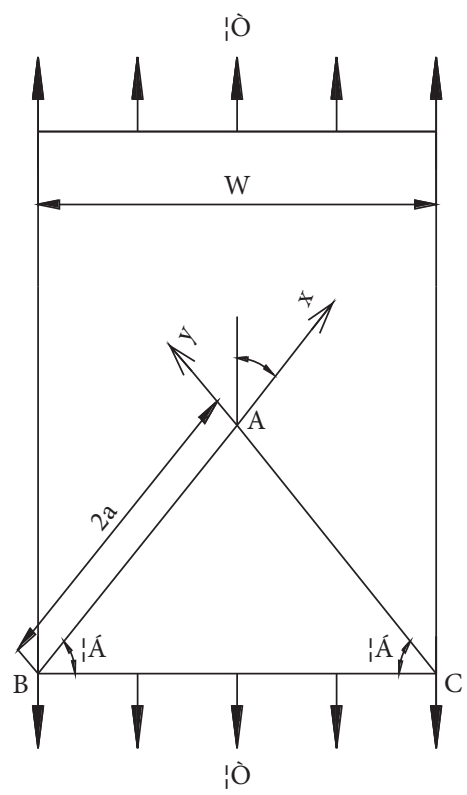

(b)

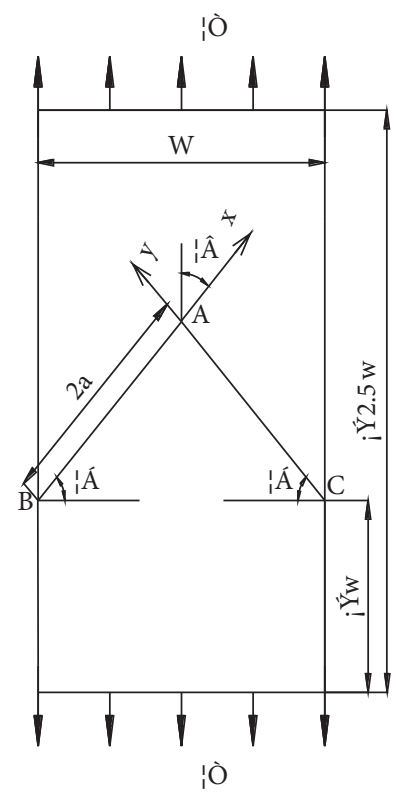

(c)

FIGURE 6: Sketch of crack distribution: (a) central symmetric cracks; (b) diagonal symmetric cracks; (c) edge symmetric cracks.

fractured rock mass, improve the overall strength of rock mass, and control the deformation of rock mass, which is widely used in the reinforcement of fractured rock mass.

3.2. Creep and Long-Term Strength. Creep is the inherent mechanical property of rock mass material, and it is the development of deformation with time under external load. When the creep load exceeds the long-term strength of rock mass, it will produce accelerated deformation characteristics. At the same time, the engineering rock mass is still in a complex underground environment for a long time, so the long-term strength determines the time-dependent deformation and stability of the rock mass structure.

At the initial stage of reinforcement, the resin rock mass structure presents transient elastic-viscous deformation, which gradually recovers and the bonding effect increases with the development of time. With the further increase in the load, the structural stress of the resin rock mass is adjusted, and the cracks creep to reach the plastic shear yield condition. As a result, the resin and the rock mass will break off and be destroy. According to the deformation composition of resin rock mass structure and the shear failure criterion of fractured rock mass, combined with the Mohr-Coulomb plastic yield condition, M-C element is used as a nonlinear creep element and connected in series with the classical Kelvin element to form the generalized Kelvin nonlinear creep element model [9]. The improved creep model has a simple structure and few components. The model parameters can be easily identified by experiments, integral transformation, polynomial fitting, and other methods. At the same time, the improved model can effectively characterize the three-stage creep characteristics of resin rock mass structure. The improved nonlinear creep model is shown in Figure 7.

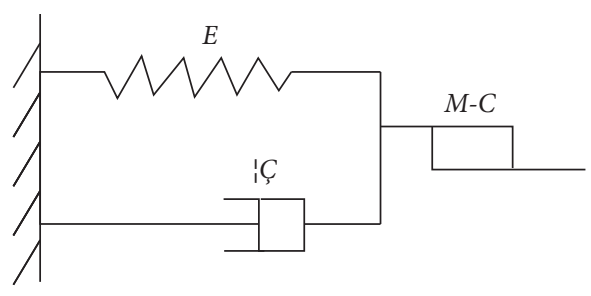

Figure 7: Nonlinearity creep model of the modified Kelvin model.

According to the theory of the nonlinear element model, the creep formulas of linear Kelvin body and nonlinear M-C body are obtained, in which the nonlinear element is mainly represented by the nonlinear viscosity coefficient.

Linear Kelvin body:

$$
\begin{aligned}
S_{i j} & =2 \eta_{\dot{e}}^{i j}+2 G e_{i j}, \\
\dot{\varepsilon} & =\frac{\sigma}{\langle\eta(t, \sigma)\rangle}\left(\frac{\tau}{\tau_{f}}\right)^{n} .
\end{aligned}
$$

(1) $<\eta(t, \sigma)>=\infty \sigma<\sigma_{g}$

(2) $\left\langle\eta(t, \sigma)>=A t\left(\ln t_{0} / t+1\right)+B\left[\arctan \left(\ln \sigma / \sigma_{t}^{\prime}\right)+\right.\right.$ $\pi / 2] \sigma \geq \sigma_{g}$

Nonlinear M-C body:

$$
\begin{aligned}
& \dot{e}_{i j}^{P}=\lambda \frac{\partial g}{\partial \sigma_{i j}}-\frac{1}{3} \dot{e}_{v o l}^{P} \delta_{i j}, \\
& e_{i j}^{p}=s_{i j}\left(\frac{1}{2 G^{p}}+\frac{1}{k} \int \mathrm{d} \lambda\right),
\end{aligned}
$$

following 


$$
\begin{aligned}
\dot{e}_{v o l}^{P} & =\lambda\left[\frac{\partial g}{\partial \sigma_{11}}+\frac{\partial g}{\partial \sigma_{22}}+\frac{\partial g}{\partial \sigma_{33}}\right], \\
\lambda & =\frac{G}{\eta} \\
s_{i j} & =k s_{i j}^{0},
\end{aligned}
$$

where $k$ is the creep experimental parameters, $A$ and $B$ are the creep experimental constants, $S_{i j}$ and $e_{i j}$ are the deviatoric stress and deviatoric strain of toughened resin rock mass structure, respectively, $\eta$ is the $e$ viscosity coefficient of toughened epoxy resin, $G$ is the shear modulus, $g$ is the plastic potential function, $\delta_{i j}$ is the Kirschner symbol, $\sigma_{11}$ and $\sigma_{33}$ are the maximum and minimum principal stress (tensile stress is positive, and compressive stress is negative), respectively, $\sigma_{g}$ is the plastic yield limit of M-C body, and $\sigma_{t}$ is the toughen the tensile strength of epoxy resin.

Mohr-Coulomb plastic yield conditions are as follows:

$$
f=\frac{1}{3} I_{1} \sin \phi-\left(\cos \theta_{\sigma}+\frac{1}{\sqrt{3}} \sin \theta_{\sigma} \sin \phi\right) \sqrt{J_{2}}
$$

following

$$
\theta_{\sigma}=\frac{1}{3} \sin ^{-1}\left[-\frac{3 \sqrt{3}}{2} \frac{J_{3}}{\left(\sqrt{J_{2}}\right)^{3}}\right]
$$

where $I_{1}$ is the first invariant of stress tensor $a$ and $J_{2}$ and $J_{3}$ are the second and third invariants of stress bias.

Combined with equations (10)-(13) and (15), the improved nonlinear creep model equation is obtained by using the principle of strain addition.

$$
e_{i j}=\frac{S_{i j}}{2 G}\left[1-\exp \left(-\frac{G}{\eta}\right) t\right]+s_{i j}\left(\frac{1}{2 G^{p}}+\frac{1}{k} \int d \lambda\right) .
$$

Considering the plastic yield failure condition of rock mass, the accelerated creep failure time of toughened epoxy resin is obtained:

$$
t_{F}=t_{0}+\frac{1}{\left[\int_{0}^{l / 2} k \varepsilon_{0} / d \exp (\pi \mathrm{d} x)-\tau_{0}\right.},
$$

where $t_{0}$ is the initial time of accelerated creep, $\tau_{0}$ is the initial bond strength of the toughened resin rock mass structure, and $\varepsilon_{0}$ is the initial strain of accelerated creep.

In the parameter identification of the improved nonlinear creep model, the model calculation parameters and long-term strength are usually obtained according to the creep curves and creep isochronal curves of different loads, The isochronous curve is shown in Figure 8 [10].

Then, by incorporating equations (17) and (18) into equation (1), the aging toughness of toughened epoxy resin is as follows:

$$
R_{T}=\frac{S_{i j}}{2 G}\left[1-\exp \left(-\frac{G}{\eta}\right) t\right]+s_{i j}\left(\frac{1}{2 G^{p}}+\frac{1}{k} \int d \lambda\right)
$$

By substituting the accelerated creep failure time into equation (19), the relationship between long-term length and toughness is further obtained as follows:

$$
F(\infty)=\frac{R_{T}}{\left\{1 / 2 G\left[1-\exp (-(G / \eta)) t_{p}\right]+\left(\left(1 / 2 G^{p}\right)+(1 / k) \int \mathrm{d} \lambda\right)\right\}}
$$

where $F(\infty)$ is the long-term length, $R_{T}$ is the toughness, $t_{p}$ is the accelerated failure time, and $k$ is the creep experimental parameters.

It is obvious that there is a correlation between toughness and long-term strength. With the increase in toughness, the long-term strength increases and the accelerated failure time increases.

\subsection{Creep Fracture Coupling Effect of Fractured Rock Mass} Structure. The fractured rock mass exists in a certain external load environment for a long time. When the stress exceeds the strength of the rock mass, the accelerated deformation of the rock mass fractures, the reduction of fracture toughness, and the increase in stress intensity factor will induce the fracture failure of the rock mass. At the same time, in the process of crack propagation, the strength of rock cracks decreases, which leads to the acceleration of creep failure, that is, creep fracture coupling deformation characteristics.

According to the characteristics of the initial creep displacement of the accelerated creep failure in equation (18), the accelerated creep failure time of the reinforced fractured rock mass in the process of crack propagation is obtained. Similarly, according to the initial displacement of the accelerated creep failure, the stress intensity factor at the tip of the I-II composite converging crack is obtained. At the same time, the fracture age toughness of epoxy resin toughened by creep fracture coupling effect can also be obtained.

\section{Experimental Study}

The stress intensity factor (SIF), crack propagation direction, accelerated failure time, and long-term strength of epoxy resin toughened and jointed rock mass were studied by laboratory experiments. In the experiment, the toughening material is mud powder particles with the mesh number of 50. The reinforced fractured rock mass is a group of symmetrical $X$-shaped fractured rock mass with the fracture width of $2 \mathrm{~mm}$. The fracture runs through the whole rock mass, and the size of rock mass is $200 \mathrm{~mm} \times 200 \mathrm{~mm}$. The mechanical parameters of rock mass are as follows: bulk density is $25 \mathrm{kN} / \mathrm{m}^{3}$, elastic modulus is $20 \mathrm{GPa}$, Poisson's ratio is 0.25 , the shear strength index is $35^{\circ}$ and $7.5 \mathrm{MPa}$, respectively, and viscosity coefficient is $300 \mathrm{MPa} \mathrm{D}$. The mixed liquid is injected into the cracks of rock mass by syringe. Finally, the displacement load of the reinforced fractured rock mass is carried out by rock servo pressure testing machine. The loading speed is $0.05 \mathrm{~mm} / \mathrm{s}$, and the load is graded until the structural failure of toughened epoxy resin rock mass. During the experiment, the mass ratio of 


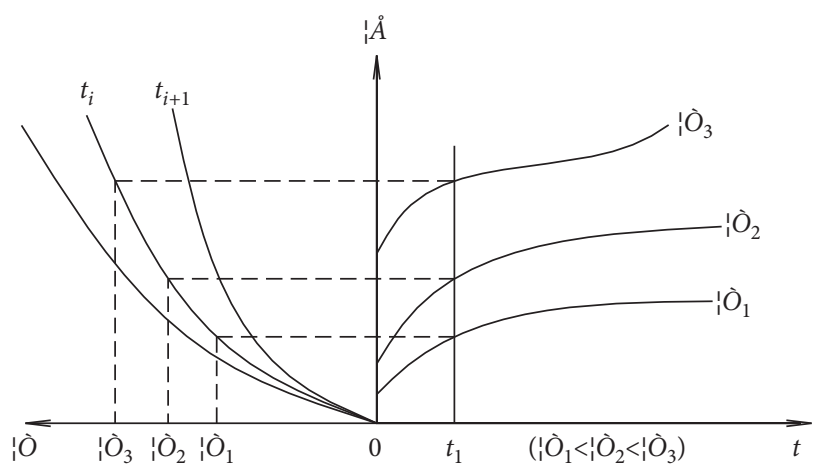

(a)

(b)

FIGURE 8: Isochronal curve and creep properties: (a) ioschronal stress-strain curve; (b) creep curve.

$\sigma$

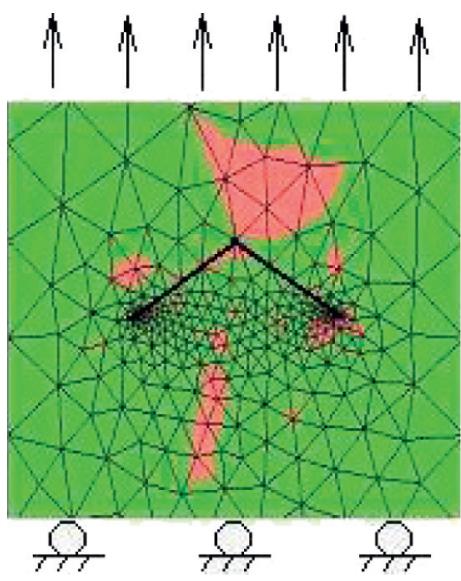

(a)

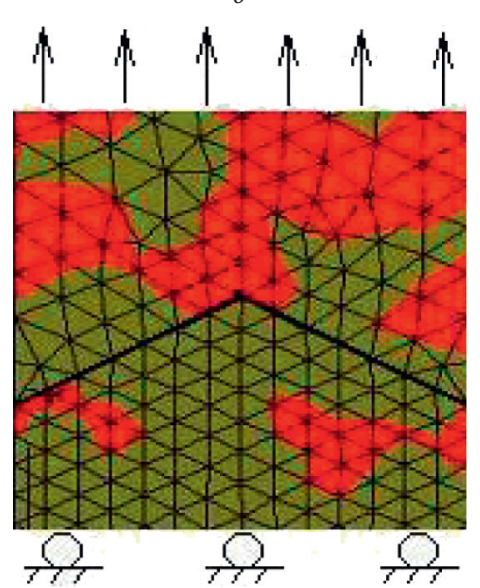

(b)

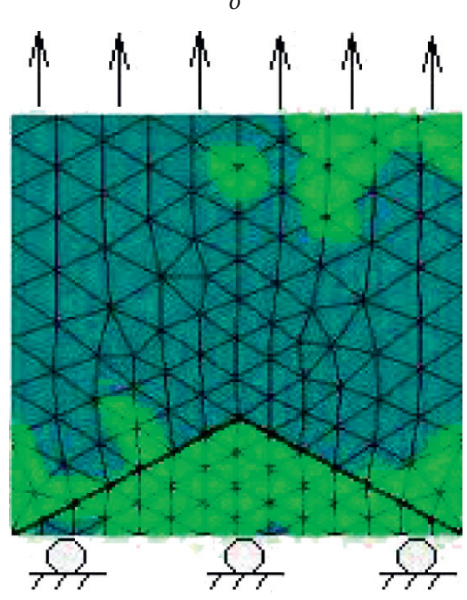

(c)

FIGURE 9: Distribution of stress concentration: (a) central symmetric cracks; (b) diagonal symmetric cracks; (c) edge symmetric cracks.

slurry powder to epoxy resin was adjusted, in which the amount of slurry powder was $5 \%, 10 \%, 15 \%, 20 \%, 25 \%$, and $30 \%$, respectively. The stress intensity factor and crack propagation direction at the crack tip are shown in Figure 9. The relationship between toughness and amount of toughened epoxy resin composite with time is shown in Figure 10.

It is obvious from Figure 10 that the amount of slurry powder has an important influence on the fracture creep mechanical properties of toughened epoxy resin. Firstly, with the increase in the amount of slurry powder, the ductility and long-term strength increase. When the amount of slurry powder reaches $20 \%$, the accelerated failure time is $80 \mathrm{~h}$ and the toughness reaches $3400 \mu \varepsilon$. With the increase in the content, the growth rate of ductility and long-term strength decreases and the accelerated failure time shortens. When the content is $30 \%$, the accelerated failure time is $70 \mathrm{~h}$ and the toughness is $2100 \mu \varepsilon$. Compared with the maximum toughness, the toughening effect is reduced by $36 \%$. Therefore, there is an optimal dosage of slurry powder as the

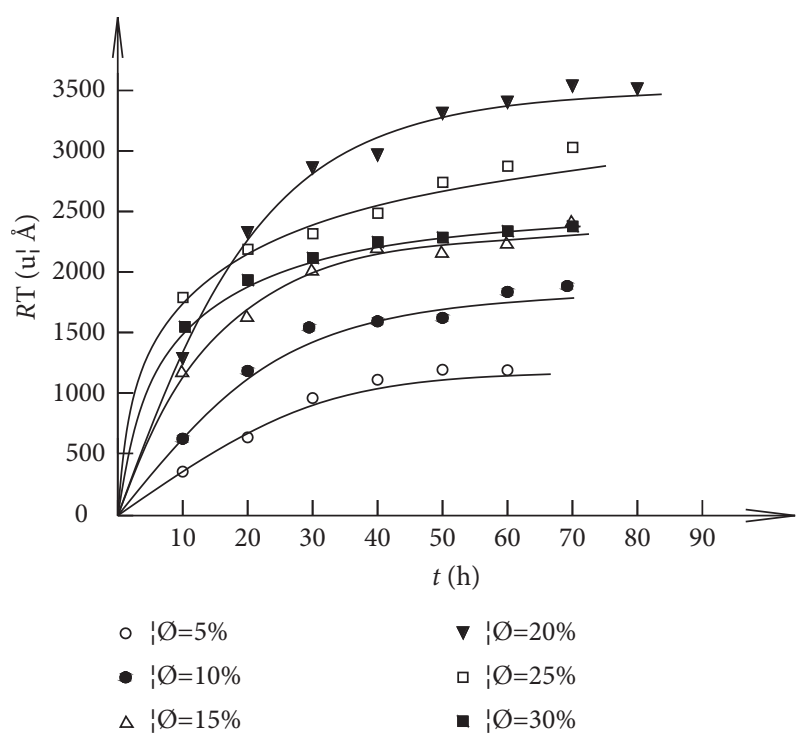

FIGURE 10: Relationship between toughness and content with time. 
toughening agent. When it exceeds the optimal dosage, the maximum toughness decreases, and the accelerated deformation and failure time decrease, and the reinforcement effect weakens. In addition, the content has an important effect on the fracture creep mechanical properties of toughened epoxy resin. Firstly, with the increase in the addition amount, the ductility and long-term strength increase, and the crack propagation speed is slow, and the expansion angle is small, and on the contrary, the crack propagation rate increases and the crack propagation angle increases.

\section{Conclusion}

According to the geometric distribution and propagation characteristics of converging cracks, the stress intensity factor of mode I-II composite crack is obtained. Combined with the weight function method, the opening displacement of the crack surface is established.

The Kelvin nonlinear creep model is proposed, which can simulate the instantaneous elastic-visco deformation and visco-plastic deformation of toughened resin rock mass. According to the Mohr-Coulomb plastic yield condition, an analytical formula for accelerated creep failure time of toughened epoxy resin was established. According to the failure characteristics of toughened epoxy resin, the toughness evaluation quantity of plastic deformation characterization was established. Combined with the timevarying characteristics of deformation and failure of toughened epoxy resin, the relationship between toughness, long-term strength, and accelerated failure time of fracture effect was obtained. The long-term strength of toughened epoxy resin under different creep loads was obtained by creep curves and isochron curves under different loads.

In the cracked rock mass reinforced with epoxy resin, the amount of slurry powder has an important influence on the long-term strength, the fracture accelerated failure time, and toughness of toughened epoxy resin, and there is an optimal amount of slur powder, so the effect of reinforcement and toughening is obvious.

\section{Data Availability}

The data used to support the findings of this study are included within the article.

\section{Conflicts of Interest}

The authors declare that they have no conflicts of interest.

\section{Acknowledgments}

The authors gratefully acknowledge the support from the Natural Science Foundation of Hunan Province (No. 2019JJ40056), the Scientific Research Foundation of Hunan Province Education Department (Nos. 18A345, 18B391, and 19B124), and the Construct Program of Applied Specialty Disciplines in Hunan Province.

\section{References}

[1] M. Cai, P. K. Kaiser, Y. Tasaka, T. Maejima, H. Morioka, and M. Minami, "Generalized crack initiation and crack damage stress thresholds of brittle rock masses near underground excavations," International Journal of Rock Mechanics and Mining Sciences, vol. 41, no. 5, pp. 833-847, 2004.

[2] N. Erarslan and D. J. Williams, "Mixed-mode fracturing of rocks under static and cyclic loading," Rock Mechanics and Rock Engineering, vol. 46, no. 5, pp. 1035-1052, 2013.

[3] G. Huimin, X. Ying, W. Weiming et al., "Study on PP/EVAL blend toughened by dynamically vulcanization," China Plastics Industry, vol. 41, no. 6, pp. 25-29, 2013.

[4] H. Yang, Y. Cui, X. Zhu et al., "Study on toughening of ABS/ MVQ blends by four vulcanization systems," Plastic Science and Technology, vol. 46, no. 12, pp. 119-122, 2018.

[5] F. Xu, W. Guo, K. Fu et al., "Toughening mechanism of Nanorubber particles in epoxy resin under different strain rates," Acta Polymerica Sinica, vol. 46, no. 9, pp. 1092-1099, 2015.

[6] B. Peng, Y. Yu, Y. Shan et al., "Study of the heat resistance performance of epoxy structural adhesive," Journal of Hunan University, vol. 40, no. 9, pp. 25-29, 2013.

[7] L. Tao, W. Min, L. Qi et al., "Study on curing kinetics of toughened modified epoxy resin and drawing of TTT diagram," Composites Science and Engineering, vol. 40, no. 10, pp. 21-29, 2020.

[8] J. Liu, P. Cao, Z. Jiang, Y.-L. Zhao, and R.-H. Cao, "Numerical simulation on effects of embedded crack on rock fragmentation by a tunnel boring machine cutter," Journal of Central South University, vol. 21, no. 8, pp. 3302-3308, 2014.

[9] J. Wang, P. Cao, J. Li et al., "Analysis of stability of tunnel slope with rheological medium under rainfall infiltration," Rock and Soil Mechanics, vol. 30, no. 7, pp. 2158-2162, 2009.

[10] Y. Wang, Y. Lv, Z. Xiao et al., "Research on sandstone creep models under chemical corrosion," Journal of China Coal Society, vol. 35, no. 7, pp. 1095-1098, 2010. 